Meta

Journal des traducteurs

Translators' Journal

\title{
Kenneth Burke, Discourse Analysis and Translation
}

\section{Elizabeth Neild}

Volume 31, numéro 3, septembre 1986

Prismes de traductions littéraires

Facets of Literary Translation

URI : https://id.erudit.org/iderudit/003700ar

DOI : https://doi.org/10.7202/003700ar

Aller au sommaire du numéro

Éditeur(s)

Les Presses de l'Université de Montréal

ISSN

0026-0452 (imprimé)

1492-1421 (numérique)

Découvrir la revue

Citer cet article

Neild, E. (1986). Kenneth Burke, Discourse Analysis and Translation. Meta,

31(3), 253-257. https://doi.org/10.7202/003700ar d'utilisation que vous pouvez consulter en ligne.

https://apropos.erudit.org/fr/usagers/politique-dutilisation/ 


\title{
KENNETH BURKE, DISCOURSE ANALYSIS AND TRANSLATION
}

\author{
ELIZABETH NEILD \\ HARVARD UNIVERSITY, CAMBRIDGE, USA
}

\begin{abstract}
If George Steiner was right when he claimed that translation is interpretation and interpretation translation, clearly translation theory and interpretation theory, both of which have burgeoned during the last few decades, will have much to contribute to each other. Interpretation, however, is best considered in the broader context of the theory of discourse. One such theory which may have some useful insights to offer translation theory is that developed during the forties and fifties by Kenneth Burke. Beginning with a theory of literature, he developed a theory of discourse which has found followers in a variety of disciplines, especially communications, but including such disparate fields as law, economics, sociology and anthropology 1 .

Many aspects of Burke's theory have relevance for translation. I will discuss three of them : first, the way he relates texts of various kinds to one another; second, his theory of interpretation ; and third, his theory of discourse, in which he emphasizes the reciprocal relationships among author, text, reader, context and purpose.

To consider first, then, the way Burke relates various kinds of texts to one another. (By kinds, I mean literary, scientific, expository and so on.) Unlike many theorists, both in translation theory and in critical theory, he emphasizes the similarities, rather than the differences, between literary and semantic texts (those whose primary purpose is to transmit ideas). He does this on the grounds that literature involves the use of language for its own sake, and therefore it uses all the resources of language to attract and keep its reader ; from the study of literature, therefore, we will learn more about the nature of language and discourse, precisely because the resources will have been used more thoroughly. Beginning with this assumption, Burke went on to develop his theory of discourse from his theory of literature. An analogous idea is true for translation : many theories of translation make a sharp distinction between literary translation and semantic translation. Jean Delisle, for example, in l'Analyse du discours comme méthode de traduction ${ }^{2}$, chooses to discuss only "pragmatic" translation, on the ground that the problems of such translation are very different from those of literary translation.
\end{abstract}

My claim is that, just as we can learn a great deal about language and discourse in general from literary language and discourse, so we can learn a great deal about translation in general from literary translation. This is because the problems encountered in the translation of literature are so much more obvious than are the problems encountered in the translation of semantic texts. The gap between the source text and the translation, in the case of literature, is obvious ; the complexity of the translator's task is evident. Thus, an examination of the task of translating this kind of text can be useful even to the translator of semantic texts.

Let us now turn to Burke's theory of interpretation. We take it as given that every translation is an interpretation. The relative importance of the part played by author, reader and text in the interpretive process is among the most controversial issues in critical theory today. There are those, like E.D. Hirsch ${ }^{3}$, who still see the author's inten- 
tion as preponderant, and others who, following Jacques Derrida, emphasize the meaning of language quite irrespective of any authorial intention ${ }^{4}$. Others again, like Roland Barthes, emphasize the active part played by the interpreter in the process ${ }^{5}$. The reason why Burke's theory is among the most compelling is that it stresses all three of these aspects of the process. He sees the author's intention and the text as of major importance, but at the same time shows how any interpretation is coloured by the interpreter's frame of reference, culture, preconceptions, personal idiosyncrasies, to name a few. His view of the active part played by the reader in the interpretive process is best expressed in his 1966 essay, "Terministic Screens" :

When I speak of "terministic screens", I have particularly in mind some photographs I once saw. They were different photographs of the same objects, the difference being that they were made with different color filters. Here something so "factual" as a photograph revealed notable distinctions in texture, and even in form, depending upon which color filter was used for the documentary description of the event being recorded ${ }^{6}$.

For Burke, then, the terms, or framework, through which we look at something determines to some extent our perception of it. If he is right, it is clear that the gap between the source text and our perception of it will be exacerbated when we put that perception into words, and even more so when we put it into words in another language and another culture.

But now to turn to Burke's theory of discourse $:$ it is a complex and many-faceted theory, developed over forty years by a far-ranging mind ; for the purposes of this paper, I will present a simplified version, limited to what Burke called the grammar ${ }^{7}$. For Burke, a text, whether a poem, a narrative, or a semantic discourse of one kind or another, has five principal aspects, which he named the pentad. In order to understand a text, we need to examine these aspects both individually and in relation to one another. First, he sees the text as an act, thus emphasizing, in contrast with many other theoreticians, the dynamic, pragmatic nature of the text. Then, he is interested in the author of the text (the agent), and how the particular author affects the nature of the text. (In literature, for example, this will include everything known about the author, his ideas, other works, life and so on - but even the most standardized government text has an author - and in this case it will be the author's nature as a particular official in a particular position which will be of interest, and not his personal idiosyncrasies.) Third, he considers the agency, the means used to produce the text. In the case of literature, this means language, imagery and all other rhetorical devices; again, however, even the most pedestrian of texts uses language in particular ways to achieve its ends.

Fourth, Burke considers scene, the all-important context in which the act takes place. Again, scene is most obvious in the case of literature, for it involves the social circumstances, period, culture, literary conventions, and so on, in which the work was written. But again, every text was written in a context, and knowing the context obviously increases our understanding of the text. Indeed, lack of understanding of the context frequently makes it difficult or impossible to interpret a text, and obviously, without such interpretation, translation is impossible.

Finally, consideration must be given to the purpose for which the text was written - so the author could express himself ? To move his audience in a particular way ? To convey information? To persuade or incite to action? And so on.

If Burke is right, since both the source text and the translation are discourse, both can be seen in the context of all five members of the pentad from the theoretical point of view. This can have practical consequences in the translation process. First, the translator can use the pentad to analyse the source text before he begins his task, so that he un- 
derstands it thoroughly in all its ramifications. He can then go on to analyse his potential translation before he begins the actual work of translating; this prior analysis will enable him to clarify in his own mind the purpose, scene and so on of his translation, which will affect the kinds of choices he will make when he actually begins to write.

Second, the analysis can be used after the fact to evaluate different translations of a single text in order to assess the reasons for the differences among them.

What, then, will the translator learn by examining the source text from the point of view of the pentad ? By examining the source text as an act, he is forced to see it as a discourse and not words and sentences. This will make him regard it as a whole - an action with a purpose, and so on, thus increasing the likelihood that he will translate the discourse as a complete discourse rather than as individual parts. Burke's dynamic model of discourse is valuable because it is precisely the dynamic and integral nature of the text which it is easy to forget as a working translator, faced with a certain output to produce in a given time.

By examining the text in relation to the agent, he is forced to clarify this important aspect of the text ; in the case of much of the work of most translators in Canada today, the agent is a faceless corporate or government official ; the translator must ask himself what consequences this fact has for the way in which the source text was produced.

By examining the agency by which the act was produced, he will for the moment go beyond the meaning of the text to look in detail at just how the message is being conveyed; even the most pedestrian document has a form, uses certain means (repetition, example, cause and effect arguments, comparison and contrast) to make its points.

By examining the scene in which the source text was produced, he is forced to inquire into contextual factors including the source culture but many other elements as well, which determine many aspects of the act, including what writing techniques are used, and so on. Finally, by examining the purpose, he is made aware, of course, of why the act was performed at all, which will in turn explain why it was performed in the way it was performed.

A complete Burkean analysis would go far beyond this : theoretically, all members of the pentad will be examined in relation to all other members. Thus, we will have, for example, the purpose-act ratio (how the purpose and act affect each other) ; the purpose-scene ratio (how purpose and scene affect each other); the purpose-agent ratio (how purpose and agent affect each other) and so on (ten ratios in all). Such a complete analysis may be unnecessary, but at least considering the source text from these points of view will put the translator in excellent posture to begin his task.

We then go on to consider our potential translation from the same five points of view. The translation is an act on the part of the translator (thus circumscribed by his abilities and limitations) using the means available in the target language (agency) in a specific scene (the target culture and the particular time and circumstances of the translation) for a specific purpose (and clearly this will be an extremely important determinant in many choices as to the nature of the translation).

Obviously, the purpose of the translation is different, sometimes very different, from the purpose of the source text. To take an obvious example, Homer's Iliad is a poem - the tragedy of Achilleus - but it evolved within the scope of a chronicle many elements of which were known to the audience, the story of the fall of Troy. The classical Greeks saw this story as history, not legend, so the poem had the double function in their society of moving its audience in relation to the fate of one man, and at the same time giving them the sense of community that is entailed in the retelling of a people's history. What is the purpose of, say, Richard Lattimore's 1951 English verse translation of the Iliad ${ }^{8}$ ? Because we do not see the chronicle on which the story is based as our his- 
tory, the work does not function in the same way to give us a sense of community ; however, it does function in a different way to achieve this end; the Iliad is recognized as the beginning of the Western literary tradition. At the same time, the modern audience can also experience the poem as a tragedy.

The purposes of a source text and a translation can differ just as sharply when the time between them is much shorter. Take, for instance, Robert Lowell's "imitations" of poems such as those of Rimbaud and Baudelaire". The original authors of "les Chercheuses de poux" and "Au lecteur" aimed to evoke a certain effect or emotion. Lowell took the original poems for his inspiration, but, as he tells us in his introduction, his purpose was to "write alive English and do what his authors might have done if they were writing their poems now and in America"10. This gives him considerable latitude in the way in which he alters or omits entire sections of the poems he imitates.

In most cases, the purpose of semantic translation is much the same for the source text and the translation ; a more important difference between the two is likely to be in scene or agency. Consider, for example, Lévi-Strauss's work on myth. Lévi-Strauss's purpose in writing, say, the four volumes of Mythologiques ${ }^{11}$, is to make others understand the structure of myth in the mainly South American societies he had studied. The purpose of his English translator is presumably the same. But when it comes to scene and agency, wide differences appear. Lévi-Strauss is writing in a "literary" culture, where his readers will not be surprised by the type of language that contains a large number of metaphors and allusions, for example. Not so his English translator. If he writes in the equivalent type of English, he will send an extra message to his readers which will encourage them to distrust the scientific validity of what Lévi-Strauss has to report. In fact, it may be partially because his translators have not really resolved this problem that Lévi-Strauss has had much less influence in anthropology in North America than might have been expected.

Although the Francophone and Anglophone scenes in Canada do not differ as markedly as the French and North American anthropology scenes mentioned above, translation from French to English in Canada does frequently entail allowing for and making choices based on the differences between the audiences of the two texts. The English Canadian audience is likely to be a great deal more geographically diverse than is the French Canadian audience, for example, and this fact would affect choices in translating certain texts.

Let us now see what we can learn about the rival merits of different translations of the same text by looking at the texts from Burke's viewpoint. It is obvious that many disputes about the value of different translations result from different assumptions about what translation is or should be. There was an example of this in an exchange in the New York Review of Books recently, between D.S. Carne-Ross, the reviewer of a translation of Dante, and a letter-writer, Irma Brandeis ${ }^{12}$. It was clear that the antagonists had quite different assumptions as to what the purpose of the translation was, and therefore made quite different judgments as to its value. (Brandeis thought the translation should provide exactly the same images and ideas as appeared in the original, while Carne-Ross assumed the aim was to produce a worthwhile poem in the spirit of the original.) The point is that the translation should be evaluated in terms of its own purpose, assuming its purpose is valid, and not in terms of some purpose the translator never had.

Another example : it is worth comparing some of the many translations of Flaubert's Madame Bovary. Among the best-known recent translations are that by Francis Steegmuller ${ }^{13}$ and that by Paul de Man ${ }^{14}$. What were the purposes of these two translators, and how did these purposes affect the nature of the translations? 
Steegmuller wanted to produce a modern version of the novel to make this work, considered so important in the history of the English novel because of the way Flaubert uses narrative point of view, accessible to the modern reader. Accordingly, he wrote a highly fluent, idiomatic text. Paul de Man, on the other hand, produced a text which is frequently neither fluent nor idiomatic. For de Man, the primary importance of Flaubert's text lies in the style. He produced a revised version of Eleanor Marx Aveling's 1886 translation $^{15}$, claiming that her version, while less fluent and idiomatic than some other versions, is closer to the cadence of Flaubert's text. In assessing the rival merits of these two translations, it is important to consider, among other things, the translators' differing purposes.

I do not know whether examining source texts and translations before the fact in this way would be useful in teaching translation, but I do think it is a relatively simple and concrete way of bringing home to students something of the complexity of the writing process. I have found, for example, in teaching English composition to Anglophones, that insisting that students provide a simplified Burkean analysis of their own composition when they present it greatly improves the level of writing; in particular it seems to help them to tailor their writing more specifically to a given audience.

Probably the two most important skills of the translator are the ability to interpret discourse in the source language, and the ability to write in the target language. The former, in addition to knowledge of the source language, requires knowledge of the subject of the text, which frequently means general knowledge - a difficult, maybe an impossible, thing to teach. Writing, however, can be taught, or at least markedly improved, and what Burke has taught us about the nature of discourse can be extremely helpful in that process.

Notes

1. This was made very evident at the interdisciplinary "Burke" conference in Philadelphia in March 1984. The most relevant works for this discussion of Burke are Counter-Statement (1931 ; 2nd ed. 1953 ; rpt. Berkeley : University of California Press, 1968); The Philosophy of Literary Form (1941 ; rev. ed. New York : Random House, 1957); A Grammar of Motives (New York : Prentice Hall, 1945); and Language as Symbolic Action (Berkeley : University of California Press, 1966).

2. Ottawa : University of Ottawa Press, 1980

3. See Validity in Interpretation (New Haven and London : Yale University Press, 1967).

4. Probably the most influential work here was initially Derrida's De la Grammatologie (Paris : Éditions de Minuit, 1967).

5. See, for example, Critique et vérité (Paris : Seuil, 1966).

6. Language as Symbolic Action, p. 45.

7. See A Grammar of Motives, especially pp. x-xvi.

8. Chicago and London : The University of Chicago Press, 1951.

9. Imitations (New York : Farrar, Straus and Cudahy, 1958).

10. Ibid., p. xi.

11. Paris : Plon, 1964-71

12. Vol. XXXII, No 2, February 14, 1955, pp. 40-41.

13. New York : Random House, 1957.

14. New York : W.W. Norton, 1965.

15. London : Vizetelly and Co., 1886 